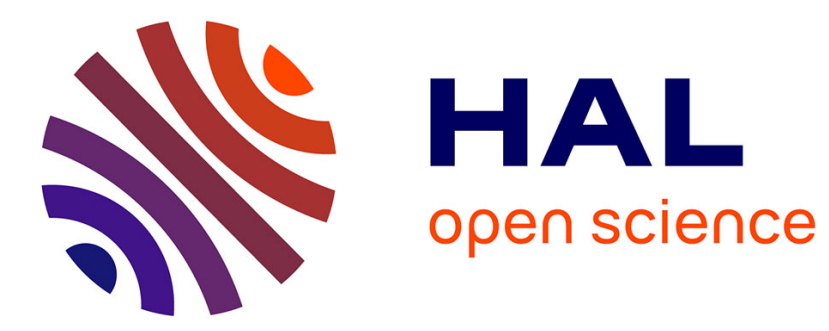

\title{
A Versatile Protocol to Generate Translocations in Yeast Genomes Using CRISPR/Cas9
}

\author{
Nicolas Agier, Aubin Fleiss, Stéphane Delmas, Gilles Fischer
}

\section{To cite this version:}

Nicolas Agier, Aubin Fleiss, Stéphane Delmas, Gilles Fischer. A Versatile Protocol to Generate Translocations in Yeast Genomes Using CRISPR/Cas9. Yeast Protocols, 2196, Springer US, pp.181198, 2021, Methods in Molecular Biology, 10.1007/978-1-0716-0868-5_14 . hal-03451882

\section{HAL Id: hal-03451882 \\ https://hal.science/hal-03451882}

Submitted on 26 Nov 2021

HAL is a multi-disciplinary open access archive for the deposit and dissemination of scientific research documents, whether they are published or not. The documents may come from teaching and research institutions in France or abroad, or from public or private research centers.
L'archive ouverte pluridisciplinaire HAL, est destinée au dépôt et à la diffusion de documents scientifiques de niveau recherche, publiés ou non, émanant des établissements d'enseignement et de recherche français ou étrangers, des laboratoires publics ou privés. 
A Versatile Protocol to Generate Translocations in Yeast Genomes using CRISPR/Cas9

Nicolas Agier ${ }^{1}$, Aubin Fleiss ${ }^{2,3}$, Stéphane Delmas ${ }^{1}$ and Gilles Fischer ${ }^{1 *}$

${ }^{1}$ : Sorbonne Université, CNRS, Institut de Biologie Paris-Seine, Laboratory of Computational and Quantitative Biology, F-75005, Paris, France.

2: Synthetic Biology Group, MRC London Institute of Medical Sciences, London, UK.

${ }^{3}$ : Institute of Clinical Sciences, Faculty of Medicine, Imperial College London, London, UK

*: Correspondence to gilles.fischer@sorbonne-universite.fr

Running Title: Generating translocations in yeast 


\begin{abstract}
Genomic engineering methods represent powerful tools to examine chromosomal modifications and to subsequently study their impacts on cellular phenotypes. However, quantifying the fitness impact of translocations, independently from base substitutions or the insertion of genetic markers remains a challenge. Here we report a rapid and straightforward protocol for engineering either targeted reciprocal translocations at the base pair level of resolution between 2 chromosomes or multiple simultaneous rearrangements in the yeast genome, without inserting any marker sequence in the chromosomes. Our CRISPR/Cas9based method consists of inducing either (i) 2 double-strand breaks (DSBs) in 2 different chromosomes with 2 distinct guide RNAs (gRNAs) while providing specifically-designed homologous donor DNA forcing the trans-repair of chromosomal extremities to generate a targeted reciprocal translocation or (ii) multiple DSBs with a single gRNA targeting dispersed repeated sequences and leaving endogenous uncut copies of the repeat to be used as donor DNA, thereby generating multiple translocations, often associated with large segmental duplications (1).
\end{abstract}

Key words CRISPR, Cas9, Yeast, Reciprocal Translocation, Segmental duplication, Chromosome Rearrangement, Structural Variation, Balanced Rearrangement, Genome Shuffling 


\section{Introduction}

The ability to engineer targeted chromosomal rearrangements is instrumental for quantifying the fitness contribution of balanced chromosomal rearrangements independently from other polymorphisms such as base substitutions or the insertion of selection markers. The classical approach used to engineer targeted rearrangements in yeast is to induce targeted DSBs in chromosomes that promote either the trans-repair of the DNA ends via homology directed repair or by non-homologous end joining (2-4). The induction of targeted DSBs has been achieved to date by a variety of technologies utilizing the $\mathrm{HO}$ and I-SceI endonucleases (510), which first requires cloning the enzyme recognition sites at the loci of interest, the Cre/Lox recombination method (11-14), which, combined with synthetic designer chromosomes can generate extensive genomic rearrangements (15-18), the use of a temperature dependent endonuclease that allows large-scale genomics rearrangements by inducing multiple DSBs (19), as well as designer proteins such as zinc finger nucleases and transcription activator-like effector nucleases (20-23).

These methods, that often rely on the use of genetic markers, are either difficult to implement or work with varying levels of efficiency. The development of the CRISPR/Cas9 technology (24), consisting of a short RNA that guides the Cas9 endonuclease to generate a DSB at the targeted genomic site, revolutionized the field of genome engineering in a wide variety of species (25). In yeast, a CRISPR/Cas9-induced DSB is efficiently repaired by homologous recombination by co-transforming the cells with a linear donor DNA that is homologous to both sides of the DSB extremities (26). A CRISPR-based approach has been used to engineer translocations in mammalian cells by introducing two DSBs in two different chromosomes and repairing them in trans using chimerical donor DNA templates carrying a selectable marker. This marker is subsequently lost by Cre/Lox recombination, leaving a single loxP scar in the chromosomes (27).

Here, we describe a CRISPR/Cas9-based protocol relying on the generation of two or more DSBs in the yeast genome and the trans-repair of DNA ends by homologous recombination using either designed or endogenous donor DNAs (1). This protocol is easy to implement and allows engineering of targeted or random translocations with high efficiency. This method does not rely on the use of genomic markers and induces rearrangements with base pair precision leaving no scar at the breakpoints. The entire workflow (Fig. 1) can be completed in approximately two weeks. The protocol presented within will guide the reader 
through the selection of suitable CRISPR target sites, the cloning of a single or a pair of gRNA sequences into a plasmid containing the $\operatorname{Cas} 9$ gene (Fig. 2), the design of linear donor DNA, the transformation of yeast cells and finally the validation of the transformants containing the engineered rearrangements by colony PCR and Pulse Field Gel Electrophoresis (PFGE). Our method is based on the pAEF5 shuttle vector that replicates in Escherichia coli and yeast (Fig. 3) and encodes the dominant drug marker HygR, as well as the Cas9 endonuclease and cloning sites for gRNAs, and therefore is applicable to any Saccharomyces strain, including wild-type isolates for which no auxotrophic mutant is available. 


\section{Materials}

All solutions and media are prepared with double-distilled water. For PCR and cloning, use molecular biology grade water.

\subsection{Bacterial Media}

1. Lysogeny Broth (LB) growth medium: $10 \%$ tryptone (w/v), $5 \%$ yeast extract (w/v), 10\% $\mathrm{NaCl}(\mathrm{w} / \mathrm{v})$. For LB agar growth medium add $2 \%$ bacto-agar (w/v). Resuspend the powders in 1 litre of double-distilled water, bring to a boil for 1 minute with frequent agitation then autoclave for 15 minutes at $121^{\circ} \mathrm{C}$. For solid media, cool down to $55^{\circ} \mathrm{C}$ and pour $20 \mathrm{~mL}$ in Petri dishes.

2. LB ampicillin selective medium: Prepare LB growth medium or LB agar growth medium depending on the requirement for the experiment. After autoclaving, cool down the medium to $55^{\circ} \mathrm{C}$ and add ampicillin to a final concentration of $100 \mu \mathrm{g} / \mathrm{mL}$. For solid media, pour 20 $\mathrm{mL}$ in Petri dishes.

\subsection{Yeast Media}

1. Yeast Peptone Dextrose (YPD) growth medium: $1 \%$ yeast extract (w/v), $2 \%$ peptone $(\mathrm{w} / \mathrm{v}), 2 \%$ dextrose (w/v). For YPD agar growth medium add $2 \%$ bacto-agar (w/v).

Resuspend the powders in $1 \mathrm{~L}$ of double-distilled water, bring to a boil for 1 minute with frequent agitation then autoclave for 15 minutes at $121^{\circ} \mathrm{C}$. For solid medium cool down to $55^{\circ} \mathrm{C}$ and pour $20 \mathrm{~mL}$ in Petri dishes.

2. YPD agar hygromycin B selective media: Prepare YPD agar growth medium. After autoclaving, cool down the media to $55^{\circ} \mathrm{C}$, add hygromycin $\mathrm{B}$ to a final concentration of 200 $\mu \mathrm{g} / \mathrm{mL}$ and pour $20 \mathrm{~mL}$ in Petri dishes.

\subsection{Bacterial and Yeast Growth Culture}

1. Grow bacteria in a microbiological incubator at $37^{\circ} \mathrm{C}$ with shaking at $220 \mathrm{rpm}$ for liquid cultures and without agitation for cells grown on solid medium.

2. Grow yeast in a microbiological incubator at $30^{\circ} \mathrm{C}$ with shaking at $150 \mathrm{rpm}$ for liquid cultures and without agitation for cells grown on solid medium.

\subsection{Microbiological Manipulation}

1. Sterile $50 \mathrm{~mL}$ plastic tube. 
2. Sterile plastic loops $(1 \mu \mathrm{L})$.

3. Sterile glass beads $(3 \mathrm{~mm})$.

4. Sterile toothpicks.

5. Electric Bunzen burner.

6. $90 \mathrm{~mm}$ Petri dishes.

\subsection{Agarose Gel Electrophoresis}

1. Agarose gel electrophoresis equipment.

2. Electrophoresis buffer: tris borate EDTA (TBE) $0.5 \mathrm{x}$. For 1 litre $5.4 \mathrm{~g}$ of tris base, $2.75 \mathrm{~g}$ of boric acid and $2 \mathrm{~mL}$ of $0.5 \mathrm{M}$ EDTA $\mathrm{pH}$ 8.0.

3. Agarose gel: $1 \%$ agarose and TBE $0.5 \mathrm{x}$ buffer. Ethidium bromide is used at the concentration recommended by the provider.

\subsection{PCR Amplification and Purification}

1. Thermo-cycler.

2. $0.2 \mathrm{~mL}$ PCR tubes.

3. $10 \mathrm{mM}$ dNTP mix.

4. High fidelity polymerase and associated buffer.

5. PCR and gel purification kit.

6. For colony PCR:

- Heat block.

- $1.5 \mathrm{~mL}$ tubes filled with $50 \mu \mathrm{L}$ of water.

- Sterile toothpicks.

- Ice.

\subsection{Cloning the gRNA Sequences in PAEF5}

1. SapI enzyme and associated buffer.

2. SpeI enzyme and associated buffer.

3. T4 DNA ligase and associated buffer.

4. $1 \mathrm{X}$ annealing buffer: $50 \mathrm{mM}$ potassium acetate, $20 \mathrm{mM}$ tris-acetate, $10 \mathrm{mM}$ magnesium acetate, $1 \mathrm{mM} \mathrm{DTT}, \mathrm{pH} 7.9$ at $25^{\circ} \mathrm{C}$.

5. $0.2 \mathrm{~mL}$ tubes.

6. $1.5 \mathrm{~mL}$ tubes. 
7. Heat block.

\subsection{Bacterial Transformation}

1. DH5 $\alpha$ competent cells.

2. Ice.

3. Heat block.

4. Incubator at $37^{\circ} \mathrm{C}$ with agitation at $220 \mathrm{rpm}$.

5. Incubator at $37^{\circ} \mathrm{C}$.

6. LB growth media.

7. LB ampicillin selective media.

\subsection{Yeast Transformations}

1. TE solution (10X): $0.1 \mathrm{M}$ tris- $\mathrm{HCl} \mathrm{pH} 7.5,0.01 \mathrm{M}$ EDTA, autoclave.

2. LiAc solution (10X) : $1 \mathrm{M} \mathrm{LiAc} \mathrm{pH} \mathrm{7.5,} \mathrm{autoclave.}$

3. PEG solution: PEG $400048 \%$ w/v (e.g. $4.8 \mathrm{~g}$ in $10 \mathrm{~mL}$ of water), filtered (0.22 $\mu \mathrm{m}$ filter).

4. LiAC/TE solution: TE solution $10 \% \mathrm{v} / \mathrm{v}, \mathrm{LiAc}$ solution $10 \% \mathrm{v} / \mathrm{v}$.

5. LiAc/TE/PEG solution: PEG solution $80 \%$ v/v, TE solution $10 \%$ v/v, LiAc solution $10 \%$ $\mathrm{v} / \mathrm{v}$.

6. Heating block at $42^{\circ} \mathrm{C}$.

7. Ice.

8. Vortex.

9. $1.5 \mathrm{~mL}$ tubes.

\subsection{PFGE}

1. CHEF-DRIII (BioRad) system.

2. SeaPlaque GTG low melting temperature agarose.

3. SeaKem GTG agarose.

4. Tris borate EDTA $0.5 \mathrm{x}$. For 1 liter $5.4 \mathrm{~g}$ of tris base, $2.75 \mathrm{~g}$ of boric acid and $2 \mathrm{~mL}$ of $0.5 \mathrm{M}$ EDTA pH 8.0.

5. Solution I: SCE 1M [sorbitol 1M, $10 \mathrm{mM}$ EDTA pH9, $100 \mathrm{mM}$ sodium citrate - adjust to pH 8.5 with citric acid $40 \%$ ], $5 \%$ ß-mercaptoethanol, $200 \mathrm{U}$ zymolyase $100 \mathrm{~T}$.

6. Solution II: 450 mM EDTA pH9, 10 mM tris-HCl pH8, $7.5 \%$ ß-mercaptoethanol. 
7. Solution III: 450 mM EDTA pH9, 10 mM tris- $\mathrm{HCl}$ pH8, $1 \%$ N-lauryl sarcosyl 10, 1 $\mathrm{mg} / \mathrm{mL}$ proteinase $\mathrm{K}$.

8. $1.5 \mathrm{~mL}$ tubes.

\subsection{Strain Storage}

1. Cryotubes.

2. Yeast storage media: $1 \%$ yeast extract (w/v), $2 \%$ peptone (w/v), $2 \%$ dextrose (w/v), $20 \%$ glycerol (v/v). Prepare 1 litre of YPD broth and a sterile solution of $80 \%$ glycerol. Mix 3:1 v/v the YPD broth and the glycerol solution.

3. $10 \mu \mathrm{L}$ sterile loops. 


\section{Methods}

In the following method the DNA sequence coding for the gRNA will be referred to as the gRNA sequence.

\subsection{Design of the gRNAs Sequence}

\subsubsection{Targeted Translocations}

The two gRNA target sequences have to be chosen as close as possible to the desired breakpoints. The website CRISPOR (http://crispor.tefor.net/) can be used for this purpose (28).

1. For each target, provide $2000 \mathrm{bp}$ of the sequence of the chromosomal region centered around the desired cut site.

2. Choose the provided version of the genome of Saccharomyces cerevisiae.

3. Choose the NGG protospacer adjacent motif (PAM) associated with the Streptococcus pyogenes Cas9 protein used here (option Sp Cas9, SpCas9-HF1, eSpCas9 1.1).

4. Click submit.

5. Choose the closest and most specific guide sequence possible next to the desired breakpoint.

\subsubsection{Multiple Translocations}

The single gRNA must be chosen considering the desired number and location of target sequences (and potential donor DNAs, see step 3.5, Note 1) in the genome.

1. Identify on both strands in the genome all target sequences of $20 \mathrm{bp}$ followed by the NGG PAM.

2. Select among these sequences the gRNA sequence with the desired number of targets in the genome.

\subsection{Construction of the gRNA Sequences}

\subsubsection{Targeted Translocations}

Two different gRNA sequences targeting two distinct chromosomes must be cloned in pAEF5 (Addgene ID 136305). There are two options available to achieve this task. 
1. The first option consists of ordering a $464 \mathrm{bp}$ synthetic double stranded DNA fragment containing both gRNA sequences (Note 2):

a. Quantity: $300 \mathrm{ng}$.

b. Delivery format: lyophilized.

Resuspend the synthetic DNA fragment:

a. spin down the lyophilised fragments for 10 seconds with a centrifuge.

b. Add water to reach a final concentration of $30 \mathrm{ng} / \mu \mathrm{L}$.

c. Incubate 1 hour at room temperature.

d. Vortex 5 seconds and spin down 10 seconds.

e. The DNA fragment is ready for cloning, go to step 3.3.2.

2. The second option is to amplify a 430 bp DNA sequence by PCR using as template the pAEF5 plasmid into which two gRNA sequences were already cloned, called pAEF6 (available on Addgene repository under the ID 136303) and as primers two oligonucleotides designed as follows (Fig. 2):

Forward oligonucleotide sequence:

$5^{\prime}$ atgcgctcttccatcNNNNNNNNNNNNNNNNNNNNgttttagagctagaaatagc 3'

Reverse oligonucleotide sequence:

5' atgegctcttcaaacNNNNNNNNNNNNNNNNNNNNgatcatttatctttcactge 3'

The 5' extremity of the two oligonucleotides is composed of a SapI restriction site (underlined in the sequence above), followed by the gRNA sequence of interest (designed as 20 Ns above). The $20 \mathrm{bp}$ at the 3' extremity of the forward primer is complementary to the structural part of the first gRNA. The $20 \mathrm{bp}$ at the 3 ' extremity of the reverse primer is complementary to the end of the second TEF promoter (Fig. 2).

PCR recommendations:

a. Use a high-fidelity DNA polymerase following the provider guidelines.

b. Use as template $20 \mathrm{ng}$ of the pAEF6 plasmid.

c. Annealing temperature for the PCR is $54^{\circ} \mathrm{C}$.

d. The elongation time should be set to amplify $500 \mathrm{bp}$ according to manufacturer instructions. 
e. Perform 30 cycles of amplification.

f. The amplification is verified by electrophoresis on a $1 \%$ agarose gel using a standard protocol.

e. The PCR product is purified by gel extraction using a standard protocol.

\subsubsection{Multiple Translocations}

A single gRNA sequence targeting multiple loci in the genome must be cloned in pAEF5. Two $23 \mathrm{bp}$ oligonucleotides that are complementary within the $20 \mathrm{bp}$ corresponding to the target sequence identified by CRISPOR need to be ordered and annealed. One oligonucleotide starts with ATC at its 5' extremity, followed by the $20 \mathrm{bp}$ of the target sequence (symbolised as $20 \mathrm{Ns}$ in the sequence below). The other oligonucleotide starts with AAC at its 5' extremity, followed by the reverse complement of the target sequence (20Ns in the sequence below). The two triplets of bases ATC and AAC are complementary to the single-strand overhangs generated by the SapI digestion of the pAEF5 plasmid, allowing to clone the double-stranded DNA target sequence in the correct orientation:

Forward oligonucleotide sequence: 5' atcNNNNNNNNNNNNNNNNNNNN 3'

Reverse oligonucleotide sequence: 5' aacNNNNNNNNNNNNNNNNNNNN 3'

Order the two oligonucleotides with the following characteristics:

a. Purification: salt free.

b. Synthesis scale: $0.01 \mu \mathrm{mol}$.

c. Delivery format: lyophilized.

d. Quality control: MALDI.

Anneal the oligonucleotides:

a. Resuspend oligonucleotides to a final concentration of $100 \mu \mathrm{M}$ in water.

b. Prepare an equimolar mix of both oligonucleotides in the annealing buffer.

c. Vortex the mix.

d. Incubate at $95^{\circ} \mathrm{C}$ for 5 minutes and let cool down slowly to room temperature.

e. The DNA fragment is ready for cloning, go to step 3.3. 


\section{$\underline{3.3 \text { Cloning gRNA Sequences }}$}

1. Prepare the pAEF5 plasmid for cloning (Note 3):

a. mix $1 \mu \mathrm{g}$ of the plasmid with $5 \mathrm{U}$ of SapI in the appropriate buffer.

b. Incubate for 1 hour at $37^{\circ} \mathrm{C}$.

c. Purify the digested plasmid by running on a standard agarose gel, cutting the high molecular band, and purifying the gel slice, using standard gel purification protocols.

2. Ligation of plasmid and gRNA sequences:

2.1. Targeted translocations:

a. Mix 300 ng of the DNA fragment containing a pair of gRNA sequences (synthetic or PCR amplified) with 5U of SapI in the appropriate buffer.

b. Incubate for 1 hour at $37^{\circ} \mathrm{C}$.

c. Purify the preparation using a standard column DNA purification protocol.

d. Mix in a $0.2 \mathrm{~mL}$ tube $100 \mathrm{ng}$ of the digested and purified plasmid backbone with 18 ng of the purified synthetic or PCR amplified DNA fragment and 5 U of T4 DNA ligase in the appropriate buffer. Adjust the final volume to $20 \mu \mathrm{L}$ with water.

e. Incubate at room temperature for at least 60 minutes before bacterial transformation.

2.2 Multiple translocations:

a. Mix in a $0.2 \mathrm{~mL}$ tube $100 \mathrm{ng}$ of the digested and purified plasmid backbone with $2 \mu \mathrm{L}$ of the annealed oligonucleotides prepared in paragraph 3.2.2 and $5 \mathrm{U}$ of T4 DNA ligase in the appropriate buffer. Adjust the final volume to $20 \mu \mathrm{L}$ with water.

b. Incubate at room temperature for at least 60 minutes before bacterial transformation.

3. Bacterial transformation:

a. Use $10 \mu \mathrm{L}$ of the ligation mix in a standard transformation protocol of Escherichia coli DH5 $\alpha$ competent cells.

b. Plate a $10^{-2}$ dilution of the cells on LB agar supplemented with ampicillin at 100 $\mu \mathrm{g} / \mathrm{mL}$.

c. Incubate the plates overnight at $37^{\circ} \mathrm{C}$.

d. Streak 12 clones on LB agar supplemented with ampicillin at $100 \mu \mathrm{g} / \mathrm{mL}$ using sterile toothpicks 
e. Incubate the plates overnight at $37^{\circ} \mathrm{C}$.

f. Inoculate $3 \mathrm{~mL}$ liquid cultures of LB supplemented with ampicillin $(100 \mu \mathrm{g} / \mathrm{mL})$ with single colonies in $15 \mathrm{~mL}$ tubes.

g. Incubate under constant shaking $(220 \mathrm{rpm})$ overnight at $37^{\circ} \mathrm{C}$.

h. In a cryotube, store $900 \mu \mathrm{L}$ of the overnight culture with $300 \mu \mathrm{L}$ of sterile glycerol 80 $\%$.

i. Vortex for 30 seconds.

j. Store at $-80^{\circ} \mathrm{C}$.

$\mathrm{k}$. The remaining volume of the culture will be used for plasmid extraction using a standard alkaline lysis protocol in order to validate the plasmid (see 3.4).

\subsection{Validation of the Clones}

Correct cloning is verified by double enzymatic restriction of the plasmid DNA:

a. Mix $1 \mu \mathrm{g}$ of plasmid with SapI (5U) and SpeI (10U) with the appropriate buffer.

b. Incubate 1 hour at $37^{\circ} \mathrm{C}$.

c. Analyse the size of the restriction fragments using electrophoresis in a $1 \%$ agarose gel (Note 4).

\subsection{Design of the Donor DNA Fragments}

\subsubsection{Targeted Translocations}

The two donor DNAs required for homologous repair upon Cas9 cutting are 90 bp long, comprising $45 \mathrm{bp}$ identical to the centromere-proximal region flanking the cut site in one chromosome and 45bp identical to the telomere-proximal region flanking the cut site on the other chromosome (Fig. 4).

1. The donor DNAs of 90 bp have the following characteristics:

a. Purification: salt free

b. Synthesis scale: $0.05 \mu \mathrm{mol}$

c. Delivery format: Lyophilized

d. Quality control: MALDI

2. For each donor DNA, anneal the two complementary 90 bp oligonucleotides: 
a. Resuspend the oligonucleotides at the final concentration of $100 \mu \mathrm{M}$ in water.

b. Prepare an equimolar mix of both oligonucleotides in the annealing buffer

c. Vortex the mix

d. Incubate at $95^{\circ} \mathrm{C}$ for 5 minutes and let cool down slowly to room temperature.

e. The DNA fragment is ready for yeast transformation, go to step 3.6

\subsubsection{Multiple Translocations:}

The identification of the number and location of donor DNAs is achieved by an in-house script that performs the following steps:

a. For each occurrence of a repeated gRNA target sequence in the genome, select an 80 bp segment centered on the cut site.

b. Use as query all possible sequences of $50 \mathrm{bp}$ comprised within this $80 \mathrm{bp}$ segment to search the genome for homologous regions with at least $90 \%$ identity and a mutated PAM and/or at least one mutation in the $20 \mathrm{bp}$ gRNA sequence.

c. Assemble a non-redundant set of donor DNAs gathering all homologous regions detected for all occurrences of the repeated gRNA target sequence.

\subsection{Yeast Transformation}

\subsubsection{Targeted Translocation}

3 transformations are performed:

i) pAEF5 (500 ng per transformation) to control for transformation efficiency.

ii) pAEF5 with the cloned gRNAs (500 ng per transformation) to control for cutting efficiency.

iii) pAEF5 with the cloned gRNAs (500 ng per transformation) and $10 \mu \mathrm{L}$ of a $90 \mu \mathrm{M}$ donor DNA solution to obtain the desired rearrangements.

\subsubsection{Multiple Translocations}

Only 2 transformations are performed:

i) pAEF5 (500 ng per transformation) to control for transformation efficiency.

ii) pAEF5 with the cloned gRNA (500 ng per transformation) to obtain the desired rearrangements. 


\subsubsection{Lithium Acetate Yeast Transformation}

All yeast transformations are performed following the standard protocol described in Gietz and Woods 2002 (29) with the following adaptations:

1. Prior to transformation, $10^{8}$ cells are washed twice in $1 \mathrm{~mL}$ of water and twice in $\mathrm{LiAC} / \mathrm{TE}$ solution.

2. The heat-shock is performed at $42^{\circ} \mathrm{C}$ for 25 minutes.

3. Centrifugations are performed at $8000 \mathrm{~g}$ for 2 minutes, at $4^{\circ} \mathrm{C}$.

4. A recovery step is necessary for the pAEF5 plasmid:

a. Pellet the cells by centrifugation.

b. Resuspend gently in $1 \mathrm{~mL}$ of YPD broth.

c. Incubate for 90 minutes at $30^{\circ} \mathrm{C}$ without agitation.

5. Cells are plated on YPD agar and selective media as described below:

a. $100 \mu \mathrm{L}$ of a $10^{-5}$ dilution is plated on YPD to assess cell viability.

b. $100 \mu \mathrm{L}$ of a $10^{-1}$ dilution is plated on selective medium.

c. The rest of the cells are plated on selective medium.

d. Incubate the plates for 3 days at $30^{\circ} \mathrm{C}$.

6. The number of colonies are counted after 3 days of incubation. (indicative results for the strains BY4741 and BY4742 are given in note 5).

7. Streak, on selective agar medium, with sterile toothpicks, 12 colonies from transformations with pAEF5 with the cloned gRNA and with or without the donor DNA for the targeted and multiple translocation transformations, respectively.

8. Incubate the plates for three days at $30^{\circ} \mathrm{C}$.

9. Store 12 colonies at $-80^{\circ} \mathrm{C}$ :

a. Fill a cryotube with $500 \mu \mathrm{L}$ of yeast storage media.

b. Pick a colony with a $10 \mu \mathrm{L}$ loop.

c. Resuspend the colony by flicking the loop 10 times in the storage media.

d. Vortex for 30 seconds.

e. Store at $-80^{\circ} \mathrm{C}$.

\subsection{Validation of the Transformants}

Karyotyping of the strains can be realized by PFGE for both targeted and multiple translocations. 
Saccharomyces cerevisiae karyotyping is done according to the standard method (30) with the following adaptation:

1. Cells are thawed on YPD agar.

2. $10 \mathrm{~mL}$ of YPD in a $50 \mathrm{~mL}$ plastic tube are inoculated with a $1 \mu \mathrm{L}$ loop of cells. This culture will be used the next day to prepare the plugs.

3. Agarose plugs are prepared using SeaPlaque GTG low melting temperature agarose.

4. PFGE is performed using a CHEF DRIII Biorad system.

5. An agarose gel is prepared using $1 \%$ Seakem GTC agarose dissolved in $0.5 \mathrm{x}$ TBE buffer.

6. The running program is the following:

a. $6 \mathrm{~V} / \mathrm{cm}$ for 10 hours with a switching time of 60 seconds

b. $6 \mathrm{~V} / \mathrm{cm}$ for $17 \mathrm{hr}$ with switching time of 90 seconds.

c. The included angle was $120^{\circ}$ for the whole duration of the run.

7. After the migration the agarose gel is stained for 30 minutes in ethidium bromide.

8. The gel is washed twice in double-distilled water.

9. A picture is taken with an imager.

For targeted translocations, an additional validation can be obtained by amplifying the junction of the rearranged chromosomes by colony PCR.

1. Design oligonucleotides to amplify $300 \mathrm{bp}$ surrounding the junctions of the expected chromosomal rearrangements.

2. Thaw candidate strains on YPD agar.

3. Incubate at $30^{\circ} \mathrm{C}$ overnight.

4. Pick cells with a toothpick.

5. Cells are resuspended in a $1.5 \mathrm{~mL}$ tube containing $50 \mu \mathrm{L}$ of sterile distilled water.

6. The tube is then incubated at $95^{\circ} \mathrm{C}$ for 5 minutes.

7. The tube is transferred directly onto ice for 5 minutes.

8. Realize a standard PCR using $5 \mu \mathrm{L}$ of the boiled cells as template (note 6).

\subsection{Loss of the Plasmid}

1. Thaw the strain from $-80^{\circ} \mathrm{C}$ on a YPD agar plate and incubate overnight at $30^{\circ} \mathrm{C}$.

2. Inoculate with a $1 \mu \mathrm{L}$ loop full of cells, $20 \mathrm{~mL}$ of YPD broth in a $50 \mathrm{~mL}$ plastic tube. 
3. Incubate the cells for 24 hours at $30^{\circ} \mathrm{C}$ with shaking at $150 \mathrm{rpm}$.

4.a Micro-manipulate 10 cells on a YPD agar plate using a standard yeast cells micromanipulation protocol.

4.b If there is no micromanipulator available, plate 100 cells from a dilution of the overnight culture on YPD agar plate.

5. Incubate the plate for 3 days at $30^{\circ} \mathrm{C}$.

6. Test the clone for the loss of the plasmid by patching them on a YPD agar plate and on a YPD agar hygromycin B selective plate (Note 7).

7. For the clones that have lost the plasmid, proceed to step 3.9.

\subsection{Storage of the Clones}

1. From a patch of cells grown on YPD agar, pick cells with a $10 \mu \mathrm{L}$ loop and resuspend them in the yeast storage medium in a cryotube.

2. Vortex for 20 seconds.

3. Store at $-80^{\circ} \mathrm{C}$. 


\section{NOTES}

1. We have generated the full catalogue of the repeated gRNA sequences and their corresponding donor DNAs. This catalogue was generated using the R64.2.1 version of the S288c Saccharomyces cerevisiae genome (https://www.yeastgenome.org/) and is available on request.

2. Sequence of the $464 \mathrm{bp}$ synthetic DNA fragment. The two gRNA sequences are designated by $20 \mathrm{~N}$ in bolds. the two SapI restriction site are indicated in bold and underlined.

GTGAAAGCTCTTCAATCNNNNNNNNNNNNNNNNNNNNGTTTTAGAGCTAGAA ATAGCAAGTTAAAATAAGGCTAGTCCGTTATCAACTTGAAAAAGTGGCACCGA GTCGGTGGTGCTTTTTTTGTTTTTTATGTCTGCGGCCGCGGTACCCAATTCGCTC TTTGAAAAGATAATGTATGATTATGCTTTCACTCATATTTATACAGAAACTTGA TGTTTTCTTTCGAGTATATACAAGGTGATTACATGTACGTTTGAAGTACAACTC TAGATTTTGTAGTGCCCTCTTGGGCTAGCGGTAAAGGTGCGCATTTTTTCACAC CCTACAATGTTCTGTTCAAAAGATTTTGGTCAAACGCTGTAGAAGTGAAAGTT GGTGCGCATGTTTCGGCGTTCGAAACTTCTCCGCAGTGAAAGATAAATGATCN NNNNNNNNNNNNNNNNNNNGTTTGAAGAGCAGAAAT

3. The pAEF5 contains the $h p h$ gene which provides resistance to hygromycin B (Figure 3 ) and was deposited in the Addgene repository under the ID 136305.

4. The expected SapI/SpeI digestion profiles for pAEF5, with one or two gRNA are presented in the table below:

\begin{tabular}{|l|l|}
\hline & pAEF5 (fragment size in bp) \\
\hline empty & $4713-4215-1925-11$ \\
\hline 1 gRNA & $6649-4215$ \\
\hline 2 gRNAs & $7059-4215$ \\
\hline
\end{tabular}

5. These results are given for the strains BY4741 and BY4742. This protocol can also be applied to natural isolates of Saccharomyces cerevisiae. However, the number of colonies 
obtained may change due to variability in the transformation efficiency of strains. After 3 days of incubation, the expected number of colonies in each plate is:

\begin{tabular}{|l|l|l|}
\hline Condition & Targeted & Multiple \\
\hline Viability (YPD agar) & $10^{1}-10^{2}$ & $10^{1}-10^{2}$ \\
\hline pAEF5 empty & $10^{3}-10^{4}$ & $10^{3}-10^{4}$ \\
\hline pAEF5 with gRNA(s) & $10^{0}-10^{1}$ & $10^{2}-10^{3}$ \\
\hline $\begin{array}{l}\text { pAEF5 with 2 gRNAs and with donor } \\
\text { DNAs }\end{array}$ & $10^{2}-10^{3}$ & \\
\hline
\end{tabular}

6. For rearrangements in repeated regions of the genome, the validation by PCR is not recommended.

7. Expected results for the loss of the plasmid:

\begin{tabular}{|l|l|l|}
\hline Plasmid & YPD agar & $\begin{array}{c}\text { YPD+Hygro B } \\
\text { agar }\end{array}$ \\
\hline Cells with pAEF5 & growth & growth \\
\hline Cells without pAEF5 & growth & no growth \\
\hline
\end{tabular}

8. The pGZ110 plasmid kindly provided by Gang Zhao and Bruce Futcher (Stony Brook University) is described in (1) and does not correspond to the plasmid deposited on the addgene website (https://www.addgene.org/browse/sequence/129168/). 


\section{Acknowledgement}

We thank Allyson Holmes and Samuel O'Donnell for reading the manuscript.

\section{References}

1. Fleiss A, O’Donnell S, Fournier T, et al (2019) Reshuffling yeast chromosomes with CRISPR/Cas9. PLOS Genetics 15:e1008332

2. Argueso JL, Westmoreland J, Mieczkowski PA, et al (2008) Double-strand breaks associated with repetitive DNA can reshape the genome. Proc Natl Acad Sci USA 105:11845-11850

3. Branzei D and Foiani M (2008) Regulation of DNA repair throughout the cell cycle. 9:297-308

4. Piazza A, Wright WD, and Heyer W-D (2017) Multi-invasions Are Recombination Byproducts that Induce Chromosomal Rearrangements. Cell 170:760-773.e15

5. Rudin N and Haber JE (1988) Efficient repair of HO-induced chromosomal breaks in Saccharomyces cerevisiae by recombination between flanking homologous sequences. Mol Cell Biol 8:3918-3928

6. Fasullo MT and Davis RW (1988) Direction of chromosome rearrangements in Saccharomyces cerevisiae by use of his 3 recombinational substrates. Mol Cell Biol $8: 4370-4380$

7. Fairhead C, Llorente B, Denis F, et al (1996) New vectors for combinatorial deletions in yeast chromosomes and for gap-repair cloning using "split-marker" recombination. 12:1439-1457

8. Dresser ME, Ewing DJ, Harwell SN, et al Nonhomologous Synapsis and Reduced Crossing Over in a Heterozygous Paracentric Inversion in Saccharomyces cerevisiae. 15

9. Richardson C and Jasin M (2000) Frequent chromosomal translocations induced by DNA double-strand breaks. 405:697-700

10. Storici F and Resnick MA (2006) The delitto perfetto approach to in vivo site-directed mutagenesis and chromosome rearrangements with synthetic oligonucleotides in yeast. Meth Enzymol 409:329-345

11. Avelar AT, Perfeito L, Gordo I, et al (2013) Genome architecture is a selectable trait that can be maintained by antagonistic pleiotropy. Nat Commun 4:2235

12. Delneri D, Colson I, Grammenoudi S, et al (2003) Engineering evolution to study speciation in yeasts. Nature 422:68-72

13. Naseeb S and Delneri D (2012) Impact of Chromosomal Inversions on the Yeast DAL Cluster. 7:42022 
14. Naseeb S, Carter Z, Minnis D, et al (2016) Widespread Impact of Chromosomal Inversions on Gene Expression Uncovers Robustness via Phenotypic Buffering. 33:16791696

15. Annaluru N, Muller H, Mitchell LA, et al (2014) Total Synthesis of a Functional Designer Eukaryotic Chromosome. 344:55-58

16. Hochrein L, Mitchell LA, Schulz K, et al (2018) L-SCRaMbLE as a tool for lightcontrolled Cre-mediated recombination in yeast. 9

17. Jia B, Wu Y, Li B-Z, et al (2018) Precise control of SCRaMbLE in synthetic haploid and diploid yeast. 9

18. Shen Y, Stracquadanio G, Wang Y, et al (2016) SCRaMbLE generates designed combinatorial stochastic diversity in synthetic chromosomes. 26:36-49

19. Muramoto N, Oda A, Tanaka H, et al (2018) Phenotypic diversification by enhanced genome restructuring after induction of multiple DNA double-strand breaks. 9

20. Brunet E, Simsek D, Tomishima M, et al (2009) Chromosomal translocations induced at specified loci in human stem cells. Proc Natl Acad Sci USA 106:10620-10625

21. Piganeau M, Ghezraoui H, De Cian A, et al (2013) Cancer translocations in human cells induced by zinc finger and TALE nucleases. Genome Res 23:1182-1193

22. Richard G-F, Viterbo D, Khanna V, et al (2014) Highly Specific Contractions of a Single CAG/CTG Trinucleotide Repeat by TALEN in Yeast. 9:95611

23. Xiao A, Wang Z, Hu Y, et al (2013) Chromosomal deletions and inversions mediated by TALENs and CRISPR/Cas in zebrafish. 41:141-141

24. Doudna JA and Charpentier E (2014) The new frontier of genome engineering,

25. Wang F and Qi LS (2016) Applications of CRISPR Genome Engineering in Cell Biology. Trends Cell Biol 26:875-888

26. DiCarlo JE, Norville JE, Mali P, et al (2013) Genome engineering in Saccharomyces cerevisiae using CRISPR-Cas systems. 41:4336-4343

27. Vanoli F, Tomishima M, Feng W, et al (2017) CRISPR-Cas9-guided oncogenic chromosomal translocations with conditional fusion protein expression in human mesenchymal cells. Proc Natl Acad Sci USA 114:3696-3701

28. Haeussler M, Schönig K, Eckert H, et al (2016) Evaluation of off-target and on-target scoring algorithms and integration into the guide RNA selection tool CRISPOR. Genome Biol 17:148

29. Gietz RD and Woods RA (2002) Transformation of yeast by lithium acetate/singlestranded carrier DNA/polyethylene glycol method. Meth Enzymol 350:87-96

30. Schwartz DC and Cantor CR (1984) Separation of yeast chromosome-sized DNAs by pulsed field gradient gel electrophoresis. Cell 37:67-75

31. Fleiss A, O’Donnell S, Fournier T, et al (2019) Reshuffling yeast chromosomes with 
CRISPR/Cas9. 415349 


\section{Figure Legends}

Fig. 1 Flowchart representing the different steps to generate both targeted and multiple translocations. The numbers on the left refer to the paragraphs in the Methods section.

Fig. 2 PCR construction of 2 gRNA sequences and cloning in pAEF5. a) The plasmid pAEF5 is digested with the SapI enzyme which cuts twice. As SapI cuts outside of its recognition site these sites are removed, leaving two extremities with 3 base overhangs (5'-gat-3') and (5'-gtt3'). b) A plasmid pAEF5 already containing two cloned gRNAs (open green boxes) is used as a template for PCR with the 2 oligonucleotides (forward and reverse oligonucleotides). This PCR will give an amplicon with SapI restriction sites (purples arrows) at its extremities. After digestion of the PCR product with SapI, two complementary overhangs for cloning in the digested plasmid are generated (5'-atc-3') and (5'-aac-3').

Fig. 3 The plasmid pAEF5 was obtained by Gibson assembly of three fragments. The first two DNA fragments (blue and red sectors) are PCR amplified from pGZ110 (Note 8). They encode the replication origins for bacteria and yeast, the bacterial ampicillin resistance cassette, the $\operatorname{Cas} 9$ and the gRNA expression cassette. This cassette contains two SapI restriction sites in opposite orientation, allowing the cloning of DNA fragments containing single or double gRNA sequences (see lower part of the figure). The third DNA fragment (green sector) is amplified from pAG32 (https://www.addgene.org/35122/) and encodes the yeast hygromycin B resistance cassette.

Fig. 4 Targeted translocations. pAEF5 cloned with 2 gRNA sequences is used to transform Saccharomyces cerevisiae and generate DBSs at two loci situated on two different chromosomes. To guide the homologous repair, two chimerical donor DNAs are used. 